\title{
Professional English in the European Context: The EHEA Challenge
}

\author{
Ángeles Linde López, Rosalía Crespo Jiménez (eds). \\ Bern: Peter Lang, 2010. 374 pages. ISBN: 978-3-0343-0088-9.
}

The aim of this volume is to collect recent "empirical experiences and reflections on the theories and practices of ESP pedagogy" (page 10), as underlined in the introduction of the book and just before providing an engaging synopsis of the evolution of ESP: its birth, definition and development throughout the last three decades, followed by a summary of the book's contents and organization. The volume is divided into three main sections. The four chapters that make up the first section "Issues in ESP approaches" focus the reader's attention on two key issues which greatly influence how ESP is approached today within the European context: on the one hand, the use of new ICT resources to improve Institutional Academic English and students' online collaboration across cultures, and, on the other, the need to adapt professional English research and teaching within the EHEA, especially in the case of such dynamic areas as Business English and English for Tourism. The following six chapters in the middle section "Specialized language analyses" analyze current communicative and linguistic issues which affect specialized languages within the new ESHE, concentrating specifically on English for textiles, Maritime English, Legal English, Scientific English and "Aeroenglish". Finally the last four chapters making up section 3 "ESP students' perceptions, attitudes and motivation" approach an increasingly challenging issue in today's ESP world: how to analyze and improve the ESP students' perceptions, attitudes and motivations.

Reviewing each contribution in more detail, Silvia Bernardini, Adriano FERraresi and Federico Gaspari, in chapter 1, look at words, parts-ofspeech distributions, lexical bundles and stance expressions in two corpora of institutional native and non-native English, and also analyse the use of English in Italian institutional websites. Their research shows evidence of a lower frequency of set phrases, personal expressions and informal style when non-native speakers employ this specialised language. In chapter 2, MARIA KUTEEva examines students' online collaboration through two case 
studies based in Lisbon and Stockholm and describes how wikis can promote effective communication for academic and professional purposes, becoming an easy-to-use accessible complement to improve students' interactive and writing skills. After this, Ángel FeLiCES LAGO sheds light upon the imbalance that exists in Spain between teaching and research within the field of Business English, offering an updated approach to the teaching of this area in this country, particularly at master level, and reviewing the situation of research into Business English at international level. The last contribution of this first quartet focuses on English for Tourism. Although in this field the adaptation to the ECTS system shows clear deficiencies, as María Luisa PÉREz CAÑADO underlines, her paper illustrates how teaching into this field can be successfully adapted to the EHEA regarding course coordination, contents, competencies, and methodological and evaluation systems.

In Section II María Isabel Balteiro Fernández reviews the internal and external processes that specialized languages use to incorporate new words from other languages, and analyses the foreign words contained in the English discourse of textiles. Chapter 6 explores the significant contribution of Maritime English to the current multicultural and multilingual international trade context. As ANA Bocanegra-VAlLe argues, Maritime English education plays an essential role in today's world economic development. Mastering this specialized language improves communication in maritime safety issues, reduces the risk of shipping accidents and its expansion grows alongside the promotion of a modern globalised shipping world. In chapter 7 Miguel Ángel CAMPOS-PARdillos observes that English, being regarded the lingua franca of the current European Judicial Space, not only transmits referential meaning but also socio-cultural and ideological connotations attached to its country of origin's legal systems, as the available learning materials and courses demonstrate. Hence, to become a "neutral" lingua franca in Europe, international bodies should be urged to eliminate some of these culturally distinct elements from English centred systems and concentrate on specifically European legal issues. Chapter 8 by Rosalía CRESPO JimÉNEZ approaches a genre of frequent use in the university world: the textbook. Applying corpus-analysis techniques, the author notices the significance of certain multi-worded terms within the overall lexical choices made, and through the extensive collocational behaviour of the word "concrete", she shows the potential of these findings to help science students improve their reading comprehension skills. In 
Chapter 9 Pascual Pérez-Paredes revises the different taxonomies to represent knowledge in LE and the complexities that characterize the areas of professional legal practice in order to remark the difficulty in offering Legal English (LE) training based on integrating approaches such as Bhatia's (2008). The paper proposes the use of ontologies as instrumental resources to help LE students to deal, among others, with domain-specific organizational features and address different professional cultures and practices. Finally, CARMEN SANCHO GUINDA approaches Aeronautical English first reviewing diachronically the methodological and contextual issues acting on aeronautical discourses, and afterwards, concentrating on ideational, interpersonal and textual strategies used in field-related specialised genres to promote the development of disciplinary aeronautical cultures.

The third and last section opens with chapter 11 by MARTA AgUILAR and ClÁUdia BARAHONA who study the collaborative writing experience of 53 Spanish engineering students in order to evaluate the effectiveness of this learning activity at university level. Research proves that accuracy and complexity improve, peer feedback is positively valued and students perceive that they learn more and can outperform their individual production. In chapter 12 ÁNGELES LINDE LÓPEZ takes a speech-act based approach to analyse the perceptions of Spanish university students' pragmatic competence in professional English. Her research demonstrates that the two testing methods used, Discourse Self-Assessment Test and Multiple-Choice Discourse Completion Test, are valid and reliable to measure learners' interlanguage pragmatic knowledge, especially when dealing with requests and apologies. Next, by analyzing the attitude of over 200 architecture students, ANA MARTíNEZ VELA shows that students' motivation on learning English can be positively influenced by integration with the international technical and scientific community. The author illustrates her view by applying these findings to the development of oral presentation skills. In the last chapter JEAN STEPHENSON and ELAINE HEWITT study the relationship between the students' foreign language anxiety and several language learning factors such as the students' self-assessment on their communicative skills' levels and both, their predictions about their grades and their actual exam performance. Their paper shows that anxiety, lack of self-confidence and negative self-perceptions are associated with poor performance expectations, particularly concerning listening and speaking results.

This book captures the reader's interest not only because it updates ESP "traditional" issues such as learner's needs and perceptions, specific 
methodologies, syllabus design and assessment methods, but also because it is aligned with the new challenges that the ESP world needs to face with escalating diligence, such as the inexorable increase of the worldwide internationalization and globalization process, the "Europeanisation" and product orientation of tertiary education, the specialization of language courses in particular professional areas, the need of specific discourse analysis models and new mechanisms to study changing, hybrid and emerging specialised languages. Upon these lines, the book provides a remarkable selection of new experiences and research insights, very useful for ESP practitioners in their process of adapting to these challenges.

Reviewed by Rosa Giménez Moreno

Universitat de València (Spain)

rosa.gimenez@uv.es

\section{REFERENCES}

Bhatia, V. (2008). "Genre analysis, ESP and professional practice". English for Specific Purposes 27: 161-174. 